\title{
Symptomatic Large Spinal Extradural Arachnoid Cyst: A Case Report
}

\author{
Ho-Yeon Cho, Sun-Ho Lee, Eun-Sang Kim, Whan Eoh \\ Department of Neurosurgery, Samsung Medical Center, Sungkyunkwan University School of Medicine, Seoul, Korea
}

\begin{abstract}
Spinal extradural arachnoid cysts (SEACs) are relatively rare cause of compressive myelopathy. SEACs can be either congenital or acquired, but the etiology and the mechanism for their development are still unclear. A number of cases have been reported in the literature, and the one-way valve mechanism is the most widely accepted theory which explains the expansion of cysts and spinal cord compression. We report two cases of SEAC in this article. Patients had intermittent, progressive cord compressing symptoms. MRI image showed large SEAC which caused compression of the spinal cord. Pre-operative cystography and CT myelography were performed to identify the communicating tract. Pre-operative epidural cystography showed a fistulous tract. The patients underwent primary closure of the dural defect which was a communicating tract. The operative finding (nerve root herniation through the tract) suggested that the SEAC developed through a checkvalve mechanism. Postoperatively, the patients had no surgical complications and symptoms were relieved. Based on our experience, preoperative identification of the communicating tract is important in surgical planning. Although surgical excision is the standard surgical treatment, primary closure of the dural defect which was a communicating tract can be an acceptable surgical strategy.
\end{abstract}

Key Words: Arachnoid cyst $\cdot$ Spinal cord $\cdot$ Meningocele

\section{INTRODUCTION}

Spinal extradural arachnoid cysts (SEACs) are the herniation of the arachnoid mater through a dural defect". They are relatively an uncommon cause of compressive myelopathy, accounting for about $1-3 \%$ of all primary spinal space occupying lesions ${ }^{9,11)}$. Symptoms are generally related to compression of the spinal cord or nerve roots. There are fluctuations in symptoms - exacerbation during exercise, erection, and Valsalva maneuver; the cerebrospinal fluid (CSF) pressure is temporarily raised and the cyst increases in size ${ }^{2)}$.

SEACs can be either congenital or acquired ${ }^{3)}$. They are thought to be associated with trauma, arachnoiditis, and neural tube defects. But in many cases, these underlying disease conditions are not detected ${ }^{2}$. Several theories have been proposed regarding the pathogenic mechanism ${ }^{2}$ : (1) Check-valve (ball-

\footnotetext{
- Received: June 22, 2015 - Revised: September 7, 2015

- Accepted: September 15, 2015

Corresponding Author: Whan Eoh, MD, PhD

Department of Neurosurgery, Samsung Medical Center, Sungkyunkwan University School of Medicine, 81 Irwon-ro, Gangnam-gu, Seoul 06351, Korea

Tel: +82-2-3410-3499, 3491, Fax: +82-2-3410-0048

E-mail:w.eoh@samsung.com

$\otimes$ This is an Open Access article distributed under the terms of the Creative Commons Attribution Non-Commercial License (http://creativecommons.org/ licenses/by-nc/3.0/) which permits unrestricted non-commercial use, distribution, and reproduction in any medium, provided the original work is properly cited.
}

valve) mechanism, (2) Hyperosmolar collection of fluid within the cyst causes free water entrance, (3) Secretion of fluid by cells lining the cyst wall.

The check-valve mechanism is the most widely accepted theory which explains the expansion of cysts and spinal cord compression $^{2,11)}$. In this report, we present two case of large (we defined large SEAC which involved more than 3 vertebral segments) extradural arachnoid cyst with dural defect-the communicating tract. The diagnosis was made by magnetic resonance imaging (MRI) and thoracolumbar epidural cystography, and the patients were treated by an operation - cyst fenestration with primary closure of the dural defect which was a communicating tract.

\section{CASE REPORT}

\section{Case 1}

A 20-year-old female patient presented with a chief complaint of progressive back pain and intermittent lower extremity weakness for 7 months. There was no postural variation and exacerbating factors of pain. But, the pain worsened during the clinical course. The lower extremity weakness was intermittent without provocative factors and it was not progressive. There was no history of any significant trauma or injections before the onset of symptoms, during the clinical course of her illness. Preoperative neurologic examination revealed bilateral 

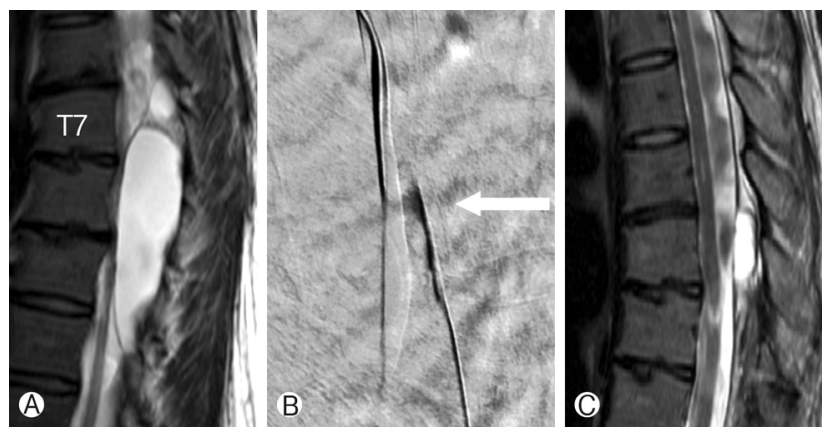

Fig. 1. Image studies of case 1. (A) Pre-operative MRI (T2WI) shows epidural cyst T7-T10 with severe cord compression. (B) Cyst was punctured at the T7 level for cystography and the contrast leaked at the T9 level to the dural sac (white arrow). (C) Follow-up MRI (T2W), two months after the operation, shows decreased size of epidural cyst after operation.

proximal weakness in the lower extremities - especially in hip flexors and knee extensors 4/5 (Medical Research Council grade, $\mathrm{MRC}$ ), but the patient did not have any sensory changes and other neurologic symptoms such as voiding difficulty and anal sphincter tone change.

MRI of the whole spine showed a large CSF-filled cystic mass with some septations causing spinal cord compression, located at T7-T10 without contrast enhancement - indicating an extradural arachnoid cyst (Fig. 1A). The patient had dural ectasia and a left lateral meningocele in the lumbosacral area. Thoracolumbar epidural cystography and computed tomography (CT) myelography revealed a contrast-filled cyst in the dorsal epidural space at T7-T10 and contrast leakage into the subarachnoid space at the lower level through the communicating tract at the T9 level, slightly to the right side. There was no communication between the small cystic lesion at $\mathrm{T} 7$ and the large cyst at T7-T10 (Fig. 1B).

The patient underwent hemi-laminectomy at T7-T10 and cyst fenestration with primary closure of the dural defect which was a communicating tract. After removal of the ligamentum flavum, a cystic mass was visualized in the epidural space. The cyst wall was thin, transparent, and multilayered with severe adhesions to the dura mater. Under a microscope, the cyst wall was opened and egress of CSF was noted. During dissection of the multilayered membrane, we found a communicating tract and a herniated nerve root at the T9 level. Along the tract and the herniated nerve rootlets, CSF leakage was identified - compatible to the finding on epidural cystography and CT myelography. Because the herniated nerve root had severely adhered to the cyst membrane, the nerve root was sacrificed and primary closure of the dural defect - communicating tract was performed. Postoperatively, the patient had no neurologic sequelae and her symptoms were diminished. The biopsy of the cyst wall membrane showed fibrocollagenous
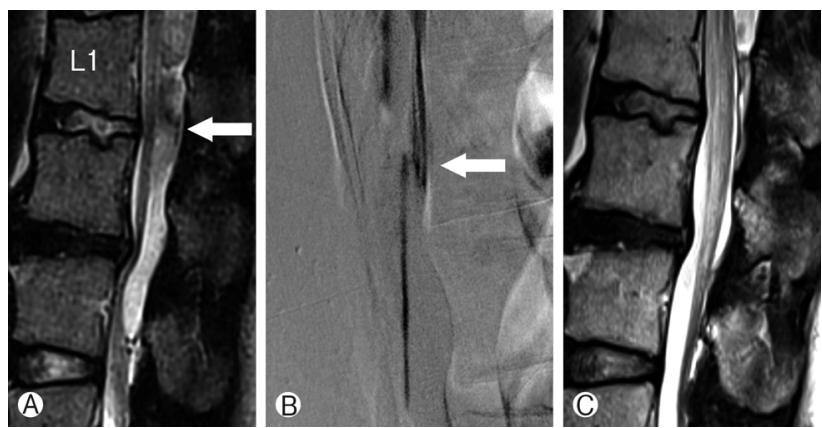

Fig. 2. Image studies of case 2. (A) Pre-operative MRI (T2WI) shows epidural cyst T11-L3 with compression of dural sac and signal voiding at L1 level (green arrow). (B) Cyst was punctured at $\mathrm{L} 2$ for cystography and contrast leakage was identified at L1 level (white arrow). (C) Follow up MRI (T2W), 5 months from operation, shows decreased size of epidural cyst after operation.

tissue consistent with an arachnoid cyst.

For two months after the operation, the patient had an uneventful postoperative period without any recurrence of symptoms. The follow-up MRI showed complete regression of the large cyst at T7-T10 and decrease in the size of the small cyst at $\mathrm{T} 7$ (Fig. 1C).

\section{Case 2}

The second case was 37 year-old male patient who was suffered from progressive right side lower extremities weakness (MRC grade 4/5) and numbness (70\% sensitivity compared to contra-lateral side), pain and tingling sense of right leg, and voiding problem (hesitancy and residual urine sense) for two years. These symptoms were intermittent and caused minimal inconvenience at the time of symptom onset. But the frequencies and severities of symptoms got worse as time goes by. At the time of admission, these symptoms were continuous. And preoperative neurologic examination revealed decreased anal tone. This patient also had no postural variation and exacerbating factors. Also, there was no history of any significant trauma before symptom onset.

MRI showed cord compressing large cystic lesion at T11L3 which was divided in two compartment by septation. And we founded signal voiding by CSF flow at L1 level in T2 weighted image (Fig. 2A). Thoracolumbar epidural cystography revealed contrast leakage to arachnoid space of lower level through communicating tract at L1 level (Fig. 2B).

This patient underwent L1 hemilaminectomy and cyst fenestration with communication tract closure. Under microscope, cyst wall was visualized at epidural space after ligamentum flavum removal. After cyst wall incision, the dural defect communication tract was visualized at L1 level, as we assumed according to preoperative evaluation. And a nerve root was 
swaying at the communication site - seemed to be a check valve. In this case, the nerve root was not adhered to cyst wall. Primary closure of communication tract without nerve root injury was done. Postoperatively, the patients had improvements in voiding problem and lower extremities weakness. And the anal tone of patient was recovered.

After 2 months from operation, the patient's symptom had improved, especially in voiding problem and weakness.

\section{DISCUSSION}

Nabors et al. ${ }^{13)}$ categorized SEACs in three major groups of meningeal cysts, non-meningeal epidural cysts, and neurenteric cysts. Meningeal cysts are further classified in 3 subgroups $^{17)}$ :

1) type 1 : extradural meningeal cyst that does not contains neural tissue

2) type 2 : extradural meningeal cyst that contains neural tissue

3) type 3 : intradural meningeal cyst - called a Tarlov cyst or a spinal nerve root diverticulum

Type 1 meningeal cysts consist of extradural arachnoid cysts (type 1a) and sacral meningoceles (type 1b). Types Ia and III cysts are mainly thoracic and posterior in location; type $1 \mathrm{~b}$ and II cysts are mainly sacral ${ }^{18)}$. Some modification has been proposed to this classification. Kumar et al. ${ }^{8)}$ have proposed a modification to include the mechanism of spinal cord herniation in type $2 \mathrm{~B}$. They have proposed a modification to divide type 1 into; type $1 \mathrm{~A}$ - cysts with communication with the thecal sac; Type $1 \mathrm{~B}$ - cysts with no communication ${ }^{16}$.

Clinical presentations of SEACs depend on the site, size of cysts, and related compression of the spinal cord or spinal nerve roots ${ }^{2}$. They could present with pain, myelopathy, radiculopathy alone, or a combination of these symptoms ${ }^{16}$. In some literatures, the symptoms are fluctuating - intermittent remissions and exacerbations ${ }^{7,10}$. Most authors proposed that this fluctuation is due to intermittent cyst expansion - due to postural change and Valsalva maneuver during daily activity which can change the CSF pressure and flow ${ }^{2,7,10,16}$. In our case 1 , the patient had intermittent lower extremity weakness and the patient recovered the muscle strength in a couple of hours from the onset. Although there was no recognizable definite exacerbating factor, the symptomatic manifestations fit this explanation. Patient of Case 2 also had symptoms which can be explained by this theory.

As mentioned above, the pathogenesis of SEACs is still unclear. However, a dural defect is assumed to be the initial event in the mechanism for development of SEACs. Some cases have a history of trauma, or infection like arachnoiditis, or iatrogenic cause which are thought to be related with $\mathrm{SEACs}^{3)}$. Other cases which do not have a history of these events are mostly considered to be congenital ${ }^{12,15}$. Even though there was no history of major trauma and congenital defect, multiple micro traumas can cause a dural tear near the nerve root sleeves because of tension across the movable dural sac and relatively fixed nerve roots ${ }^{3,5,19)}$. In the cases presented in this article, the patients had no history of trauma, infection, or injection. Intraoperative finding showed that the dural defect was located near the T9 (case 1) and L1 (case 2) nerve root sleeve. Considering these findings, the initial dural defect may not be congenital.

Sangala et al. ${ }^{16)}$ reported a SEAC at the L1 level with L1 nerve root prolapse into the cyst. They reported about a herniated nerve root which was trapped by the CSF flow and that nerve root adhesion to the cyst wall can be a factor that prevents nerve root reduction. Choi et al..$^{3)}$ reported a similar theory in their case report. These factors can result in a checkvalve mechanism which causes enlargement of SEACs. In our case 1, the T9 nerve root was adhered to the cyst wall and could not be dissected away from the cyst wall without causing nerve root injury. Also, the herniated nerve root was swaying due to the CSF flow - acting as a check valve. In case 2, the nerve root was not adhered to cyst wall. But the nerve root was swaying through the dural defect acting like a check valve.

Traditionally, MRI and CT myelography are considered as the diagnostic imaging studies. These studies show a space occupying lesion in the extradural space which was filled with CSF with or without an enlarged spinal canal, widened foramina, increased interpedicular distance, slender pedicles and lamina, and posterior scalloping of the vertebral bodies. Plain X-ray film can also be useful - illustrating bony changes. Recently, various imaging studies have been proposed for diagnosis and identification of the communication of SEACs. Delayed (6-hr) CT myelography and assessment of the density of the cyst are helpful in identifying the presence of the communicating tract $^{16}$. Doita et al..$^{4)}$ demonstrated the mechanism of spinal cord compression by SEACs. Neo et al. ${ }^{14)}$ reported that the preoperative cine-MRI scan detected the dural defect in a patient with a spinal extradural arachnoid cyst. In our cases, we performed thoracolumbar epidural cystography to identify the communication site. Epidural cystography showed contrast filling of the SEAC and leakage from the thecal sac through the communicating tract. Also, this study was important in surgical planning, especially in case 2 . And the operative finding was compatible with the thoracolumbar epidural cystography finding.

The standard treatment for SEACs is surgical management that includes complete resection of the cyst wall and closure of any communication between the cyst and the subarachnoid space after laminectomy of the affected vertebrae ${ }^{11)}$. When 
the communication site is not detected preoperatively or when the dural defect is located on the lateral side, extensive exposure is needed for treating the cysts. To reduce the complications of laminectomy such as invasion of the hematoma and scar tissue into the spinal canal, postoperative instability, and subluxation or kyphotic deformity of the spine ${ }^{16}$, laminoplasty is required ${ }^{11)}$. Considering these requirements, Miyakoshi et al. ${ }^{11)}$ recommended T-saw laminoplasty to obtain sufficient exposure and space and to reduce the complications of laminectomy. Sangala et al. ${ }^{16)}$ proposed surgical planning depending on the presence or absence of a communication with the thecal sac to reduce the risk of wide exposure and to obtain good results. In cysts without a communicating tract, excision of the cyst wall should be the surgical goal. In cysts with a communicating tract, obliteration of the communication tract should be the aim. In this respect, preoperative identification of the communication is very important. In the cases presented in this article, we identified the communicating tract and performed cyst fenestration with primary closure of the dural defect. Especially in case 2, we only performed one level lamine ctomy according to preoperative evaluation and we acquired acceptable outcome. Two months from the operation, the patient had no recurrent symptoms and surgical complications. Also, the follow-up MRI showed a satisfactory result. Some authors have demonstrated other techniques such as the Twist technique ${ }^{9}$. These techniques are aimed at treating SEACs with a smaller exposure - decreasing the risk of injury to the adjacent structures.

\section{CONCLUSION}

We experienced two case of SEAC recently and performed cyst fenestration with primary closure of the communicating tract. Imaging studies, thoracolumbar epidural cystography and CT myelography directly visualized the communicating tract, were important in surgical planning. During the operation, we found that the nerve root was swaying through the communication tract and this operative finding suggested another important aspect in the pathogenesis of SEACs - the herniated nerve root acted as a check valve. Although total cyst excision is the widely accepted standard treatment, preoperative identification of the communicating tract and primary closure of the dural defect which was a communicating tract with cyst fenestration can be an acceptable surgical strategy.

\section{REFERENCES}

1. Amhaz HH, Fox BD, Johnson KK, Whitehead WE, Curry DJ,
Luerssen TG, et al: Postlaminoplasty kyphotic deformity in the thoracic spine: case report and review of the literature. Pediatr Neurosurg 45:151-154, 2009

2. Choi JY, Kim SH, Lee WS, Sung KH: Spinal extradural arachnoid cyst. Acta Neurochir (Wien) 148:579-585, 2006

3. Choi SW, Seong HY, Roh SW: Spinal extradural arachnoid cyst. J Korean Neurosurg Soc 54:355-358, 2013

4. Doita M, Nishida K, Miura J, Takada T, Kurosaka M, Fujii M: Kinematic magnetic resonance imaging of a thoracic spinal extradural arachnoid cyst: an alternative suggestion for exacerbation of symptoms during straining. Spine (Phila Pa 1976) 28:E229233, 2003

5. Hatashita S, Kondo A, Shimizu T, Kurosu A, Ueno H: Spinal extradural arachnoid cyst--case report. Neurol Med Chir (Tokyo) 41:318-321, 2001

6. Hida S, Naito M, Arimizu J, Morishita Y, Nakamura A: The transverse placement laminoplasty using titanium miniplates for the reconstruction of the laminae in thoracic and lumbar lesion. Eur Spine J 15:1292-1297, 2006

7. Krings T, Lukas R, Reul J, Spetzger U, Reinges MH, Gilsbach $\mathrm{JM}$, et al: Diagnostic and therapeutic management of spinal arachnoid cysts. Acta Neurochir (Wien) 143:227-234, 2001

8. Kumar R, Taha J, Greiner AL: Herniation of the spinal cord. Case report. J Neurosurg 82:131-136, 1995

9. Lee SH, Shim HK, Eun SS: Twist technique for removal of spinal extradural arachnoid cyst: technical note. Eur Spine J 23:17551760, 2014

10. McCrum C, Williams B: Spinal extradural arachnoid pouches. Report of two cases. J Neurosurg 57:849-852, 1982

11. Miyakoshi N, Hongo M, Kasukawa Y, Shimada Y: Huge thoracolumbar extradural arachnoid cyst excised by recapping T-saw laminoplasty. Spine J 10:E14-18, 2010

12. Myles LM, Gupta N, Armstrong D, Rutka JT: Multiple extradural arachnoid cysts as a cause of spinal cord compression in a child. Case report. J Neurosurg 91:116-120, 1999

13. Nabors MW, Pait TG, Byrd EB, Karim NO, Davis DO, Kobrine AI, et al: Updated assessment and current classification of spinal meningeal cysts. J Neurosurg 68:366-377, 1988

14. Neo M, Koyama T, Sakamoto T, Fujibayashi S, Nakamura T: Detection of a dural defect by cinematic magnetic resonance imaging and its selective closure as a treatment for a spinal extradural arachnoid cyst. Spine (Phila Pa 1976) 29:E426-430, 2004

15. Rimmelin A, Clouet PL, Salatino S, Kehrli P, Maitrot D, Stephan $\mathrm{M}$, et al: Imaging of thoracic and lumbar spinal extradural arachnoid cysts: report of two cases. Neuroradiology 39:203-206, 1997

16. Sangala JR, Uribe JS, Park P, Martinez C, Vale FL: Nerve root prolapse into a spinal arachnoid cyst--an unusual cause of radiculopathy. Clin Neurol Neurosurg 111:460-464, 2009

17. Suryaningtyas W, Arifin M: Multiple spinal extradural arachnoid cysts occurring in a child. Case report. J Neurosurg 106:158161, 2007

18. Tarlov IM: Spinal perineurial and meningeal cysts. J Neurol Neurosurg Psychiatry 33:833-843, 1970

19. Tureyen K, Senol N, Sahin B, Karahan N: Spinal extradural arachnoid cyst. Spine J 9:E10-15, 2009 